\title{
Validation and application of the Chinese version of the Perceived Stress Questionnaire (C-PSQ) in nursing students
}

\author{
Yi Luo ${ }^{1}$, Boxiong Gong ${ }^{2}$, Runtang Meng ${ }^{\text {Corresp.. }}{ }^{3}$, Xiaoping Cao ${ }^{1}$, Shuang Tang ${ }^{4}$, Hongzhi Fang ${ }^{5}$, Xing Zhao \\ ${ }^{6}$, Bing Liu ${ }^{7}$ \\ ${ }^{1}$ School of Nursing, Ningbo College of Health Sciences, Ningbo, People's Republic of China \\ 2 Department of Oncology, Taihe hospital, Hubei University of Medicine, Shiyan, People's Republic of China \\ 3 Department of Preventive Medicine, School of Health Sciences, Wuhan University, Wuhan, People's Republic of China \\ 4 Department of Nursing, Renmin hospital, Hubei University of Medicine, Shiyan, People's Republic of China \\ 5 Department of Anaesthesiology, ShanDong Provincial Western Hospital, Jinan, People's Republic of China \\ 6 Department of orthopaedics, Taihe hospital, Hubei University of Medicine, Shiyan, People's Republic of China \\ 7 Centre of Health Administration and Development Studies, Hubei University of Medicine, Shiyan, People's Republic of China \\ Corresponding Author: Runtang Meng \\ Email address: mengruntang@whu.edu.cn
}

Objective. To translate the Perceived Stress Questionnaire (PSQ) into Chinese, validate its reliability and validity in nursing students and investigate the perceived stress level of nursing students. Method. Forward- and back-translation combined with expert assessment and cross-cultural adaptations were used to construct the Chinese version of the Perceived Stress Questionnaire (C-PSQ). This research adopted a stratifiedsampling method among 1519 nursing students in 30 classes of Ningbo College of Health Sciences to assess the reliability and validity of the C-PSQ. Among them, we used the Recent C-PSQ (only the last month). Results. The C-PSQ retained all 30 items of the original scale. Principal component analysis extracted five factors that explained $52.136 \%$ of the total variance. The S-CVI/Ave was 0.913 . Concurrent validity was 0.525 and 0.567 for anxiety and depression respectively. The results of the confirmatory factor analysis were as follows: $\chi^{2} / d f=4.376, \mathrm{RMR}=.023, \mathrm{GFI}=.921, \mathrm{AGFI}=.907, \mathrm{CFI}=.916, \mathrm{RMSEA}=.048$, $\mathrm{PNFI}=.832, \mathrm{PGFI}=.782, \mathrm{CN}=342$ and $\mathrm{AIC} / \mathrm{CAIC}=.809$. The scale's Cronbach's alpha was 0.922, and Cronbach's $\alpha$ of each dimension was 0.899 (worries/tension), 0.821 (joy), 0.688 (overload), 0.703 (conflict), 0.523 (self- realization). The correlation coefficient between the first and second test, the first and third test, and the second and third test was 0.725 , 0.787 , and 0.731 , respectively. Mean values and distribution of overall PSQ index in nursing students was $0.399 \pm 0.138$. Different demographic factors were significantly associated with the perceived stress of nursing students. Conclusion. The C-PSQ has an appropriate reliability and validity, which means that the scale can be used as a universal tool for psychosomatic studies. The perceived stress of nursing students was relatively high. Further studies are needed. 
1 Validation and application of the Chinese version of the Perceived Stress Questionnaire (CPSQ) in nursing students

3 Yi Luo ${ }^{1, \dagger}$, Boxiong Gong ${ }^{2, \dagger}$, Runtang Meng ${ }^{3, \dagger, *}$, Xiaoping Cao ${ }^{1}$, Shuang Tang ${ }^{4}$, Hongzhi Fang

$4 \quad 5$, Xing Zhao ${ }^{6}$ and Bing Liu ${ }^{7}$

51 School of Nursing, Ningbo College of Health Sciences, Ningbo, People's Republic of China

62 Department of Oncology, Taihe hospital, Hubei University of Medicine, Shiyan, People's

$7 \quad$ Republic of China

83 Department of Preventive Medicine, School of Health Sciences, Wuhan University, Wuhan,

$9 \quad$ People's Republic of China

104 Department of Nursing, Renmin hospital, Hubei University of Medicine, Shiyan, People's Republic of China

6 Department of orthopaedics, Taihe hospital, Hubei University of Medicine, Shiyan, People's Republic of China

* Corresponding author: Runtang Meng, mengruntang@163.com or mengruntang@whu.edu.cn

$\dagger$ These authors contributed equally to this work.

\section{Abstract}

Objective. To translate the Perceived Stress Questionnaire (PSQ) into Chinese, validate its reliability and validity in nursing students and investigate the perceived stress level of nursing students. Method. Forward- and back-translation combined with expert assessment and crosscultural adaptations were used to construct the Chinese version of the Perceived Stress Questionnaire (C-PSQ). This research adopted a stratified sampling method among 1519 nursing students in 30 classes of Ningbo College of Health Sciences to assess the reliability and validity of the C-PSQ. Among them, we used the Recent C-PSQ (only the last month). Results. The CPSQ retained all 30 items of the original scale. Principal component analysis extracted five factors that explained $52.136 \%$ of the total variance. The S-CVI/Ave was 0.913 . Concurrent validity was 0.525 and 0.567 for anxiety and depression respectively. The results of the confirmatory factor analysis were as follows: $\chi^{2} / d f=4.376, \mathrm{RMR}=.023, \mathrm{GFI}=.921, \mathrm{AGFI}=.907$, $\mathrm{CFI}=.916, \mathrm{RMSEA}=.048, \mathrm{PNFI}=.832, \mathrm{PGFI}=.782, \mathrm{CN}=342$ and $\mathrm{AIC} / \mathrm{CAIC}=.809$. The scale's Cronbach's alpha was 0.922 , and Cronbach's $\alpha$ of each dimension was 0.899 (worries/tension), 0.821 (joy), 0.688 (overload), 0.703 (conflict), 0.523 (self- realization). The correlation coefficient between the first and second test, the first and third test, and the second and third test was $0.725,0.787$, and 0.731 , respectively. Mean values and distribution of overall PSQ index in nursing students was $0.399 \pm 0.138$. Different demographic factors were significantly associated with the perceived stress of nursing students. Conclusion. The C-PSQ has an appropriate reliability and validity, which means that the scale can be used as a universal tool for psychosomatic studies. The perceived stress of nursing students was relatively high. Further 
41

42

studies are needed.

\section{Introduction}

Nursing students experience a substantial amount of stress (Al-Zayyat \& Al-Gamal 2014; Patterson 2016). These perceived stresses increases in the process of learning professional nursing knowledge (Lamaurt et al. 2011; Levesque 2015). Their stress originates from daily life events, the rigorous study of theories, and nursing clinical practice. On the one hand, nursing students must spend plenty of time and energy learning complicated professional topics, which makes them feel isolated, helpless and nervous (Yearwood \& Riley 2010). On the other hand, clinical practice is performed in the hospital, which has a complicated environment (heavy workload, quick tempo, highly concentrated and intense competition) and depressed atmosphere (birth, senility, illness and death); nursing staff is a high-risk occupation in China. Nursing students can feel anxious, as they are constantly exposed to the sad emotions of the patients and their family members as well as fear of the risk of needle stick injuries (Moscaritolo 2009; Shearer \& Davidhizar 1998). Moreover, nursing practice requires nursing students to possess a high medical and humanistic quality; nursing students can experience great stress while studying to meet these requirements because of their fear of lacking professional knowledge and skills (Moridi et al. 2014; Sheu et al. 2002).

For most Chinese students, stress also results from characteristics of the Chinese education system. Inequality exists in the allocation of educational resources, and the educational resourceutilization-rate is low (Rong \& Shi 2001). In addition, as a result of the rapid expansion of the Chinese educational system, graduates' employment rate has become lower than before, which is uncommon in the development of higher education worldwide (Wen 2005). Nursing students in China experience substantial stress. They not only tolerate the stress from academic studies and clinical practice but also from the risk of failing to find a job.

Excessive stress has negative effects on nursing students, including psychological disorders, physiological diseases and social maladjustments. Research indicates that stress can significantly predict depressive symptoms, the prevalence of depression has reached 32.6\% among college nursing students (Chen et al. 2015). Another study shows that nursing students have a much higher probability of committing suicide than other students (Goetz 1998). Excessive stress can therefore seriously affect nursing students' mental health and can cause physical injury. Moreover, it has been shown that stress increases the incidence of ulcerative colitis, sleeping difficulties and fatigue syndrome, which means that stress has a negative influence on students' health (Asencio-López et al. 2015; Levenstein et al. 2000; Levenstein et al. 2015; Waqas et al. 2015). Poor mental and general health may not only lead to a low capacity to study and cope in students (Beddoe \& Murphy 2004) but also change students' determination to engage in nursing practice, which may have poor physic-psycho-social responses (Chen \& Hung 2014; Watson et al. 2009).

The problems mentioned above present many challenges to nursing students as well as nursing educators. Nursing educators can gradually relieve students' stress and negative emotions through effective measures when they detect the students' perceived stress and recognize their nervousness and anxiety (Hamaideh et al. 2016). The current study adopted the Perceived Stress Questionnaire (PSQ) to investigate nursing students' perceived stress level. In 1993, Susan 
83

Levenstein developed the PSQ and published it in English and Italian; it has shown good reliability and validity. The PSQ has two forms - the General PSQ and Recent PSQ. The General form measures the perceived stress based on the subjects' feeling in the long run ("in general, during the last two years"), while the Recent form evaluates according to events that happened in only the last month ("during the last month") (Levenstein et al. 1993). Two forms of the PSQ differ only in the defined time range, and other content are identical. The scale has 30 items that cover seven dimensions including harassment, overload, irritability, lack of joy, fatigue, worries and tension. In addition to the English and Italian versions, the scale has been translated into other languages including German (Fliege et al. 2001; Fliege et al. 2005; Kocalevent et al. 2007; Kocalevent et al. 2011a; Kocalevent et al. 2011b), French (Consoli et al. 1996), Spanish (Montero-Marin et al. 2014; Sanz-Carrillo et al. 2002), Swedish (Bergdahl \& Bergdahl 2002; Rönnlund et al. 2015), Norwegian (Østerås et al. 2015), Greek (Karatza et al. 2014) and Thai (Ross et al. 2005; Wachirawat et al. 2003). We preliminarily focus on versions that provide relatively complete psychometric characteristics.

The PSQ belongs to a universal scale (Kocalevent et al. 2007) which is commonly used to measure perceived stress, it can be applied to the medical field and other fields (Levenstein et al. 1994). It provided an effective scale for the current study, as it has been used previously to measure perceived stress in medical students (Montero-Marin et al. 2014). Universal as the scale is, it can be used to measure the perceived stress of not only nursing students, medical students and inpatients (Fliege et al. 2005) but also that of the entire medical staff, such as doctors, nurses and managers. Moreover cannot but raise, the Perceived Stress Scale (PSS) is another earlier universal scale for measuring stress perception and is currently translated into near 30 language versions (2017), including the Chinese PSS, other than English on the basis of Laboratory for the Study of Stress, Immunity and Disease. Indeed, the major difference between the PSS and the PSQ lies solely with measurement dimensions, dimensions of the latter are more focused on individuals appraise situations in their lives as stressful to report whether there seem to be unpredictable, uncontrollable or overloaded during the previous month (Lee 2012; Levenstein et al. 1993). According to items, there are three versions of the PSS (PSS-14, PSS-10 and PSS-4).

However, no Chinese version of the PSQ had been published until we introduced the Chinese version of the PSQ (C-PSQ). The C-PSQ was validated in a large sample of Chinese nursing students to measure their level of perceived stress, thus proving the scale had an appropriate reliability and validity. Once the PSQ has been introduced to China, people will be able to use it to measure the perceived stress level of nursing students and other medical students as well as that of medical workers and other groups of people whose level of perceived stress needs to be studied. We believed that the development of the C-PSQ would provide a firm foundation for related studies in China.

\section{Method}

2.1. Introducing the scale

The PSQ was translated using forward and back translation based on the integrated method (Sidani et al. 2010) and Brislin's translation model (Brislin 1970; Doris et al. 2003) after receiving permission from the original author-Susan Levenstein. Firstly, forward translation was independently carried out by two bilingual translators whose first language was Chinese. 
125

126

127

128

129

130

131

132

133

134

135

136

137

138

139

140

141

142

143

144

145

146

147

148

149

150

151

152

153

154

155

156

157

158

159

160

161

162

163
One translator had abundant psychological knowledge and knew the scale, while the other translator was sensitive to expressions of language. Secondly, the translator with abundant psychological knowledge and an English scholar compared and examined the two scales together to finalize a draft. Thirdly, two English language scholars who knew nothing about the English version of the PSQ back-translated the draft to an English version. Fourthly, the two backtranslated scales were compared, and the back-translated version was finalized. Fifthly, the researcher compared and judged the differences between the back-translated manuscript and the original scale, forward- and back-translated different items again and finalized the questionnaire. Additionally, we consulted 10 scholars who are experts in the development and validation of scales from Wuhan University, Yunnan University and Ningbo College of Health Sciences. Taking the experts' suggestions and the results of the forward and backward translation into consideration, we developed the C-PSQ after several rounds of discussion. For the specific processes, refer to Figure 1.

[Figure 1 near here.]

Figure 1 Flow chart of introducing the C-PSQ.

The C-PSQ maintains the item order and scoring method of the original English version of the PSQ, using a four-point Likert Scale and asking how often (on a scale from 1, 'almost never', to 4, 'usually') each item occurred. The lowest score on the original scale is 30 , and the highest score is 120. The final score, PSQ index, is (raw score-30)/90 and ranges from 0-1, with higher scores indicating greater stress. Several items $(1,7,10,13,17,21,25,29)$ were reverse scored (Levenstein et al. 1993). There are presently two ways to cut off score concerning PSQ index evaluation. Two cut-off scores of the PSQ index were yielded in recent research by using the PSQ index mean score (M) and standard deviation (SD) of the population studied in order to divide the subjects into three groups, low level $(\leq \mathrm{M} \pm \mathrm{SD})$, moderate level $(>\mathrm{M} \pm \mathrm{SD}$ and $\leq \mathrm{M} \pm 2 \mathrm{SD})$ and high level ( $>$ M \pm 2 SD) of perceived stress(Bergdahl \& Bergdahl 2002; Kocalevent et al. 2007). Three cut-off scores of the PSQ index is divided according to quartile in earlier research (Levenstein et al. 1993; Sanz-Carrillo et al. 2002).

\subsection{Ethics statement}

The medical ethics committee of Wuhan University School of Medicine (WUSM) approved this study. The current study adhered to the rules of the Declaration of Helsinki and its revised version as well as the rules of bio-medical journals. Additionally, this study was approved by the surveyed school and students in Ningbo College of Health Sciences.

\subsection{Research}

The current study includes general information on and the perceived stress of nursing students. The newly developed C-PSQ was used to measure perceived stress. Among them, we used the Recent C-PSQ (only the last month). We interviewed 9 students prior to conducting the survey formally to assess whether the general information form and language of the C-PSQ were suitable and reasonable in line with the Chinese context. We then revised the general information form based on the results of the interview and adjusted the text font, size and line spacing to 
164

make it easier to read to avoid information bias (Althubaiti 2016).

The final general information form included the following information: sex, age, home location (city, town, village), single-child status, admission time (2015, 2014, 2013), initial educational degree (secondary school, high school), clinical practice experience, part-time job status, frequency of going back home, physical health, mental health, attitude towards nursing job prospects, greatest source of stress in college life (studies, employment, interpersonal relationships, love life, financial state, family), and the most often used coping skill (adjusting psychology, solving problems, escaping). Meanwhile, to test for criterion (concurrent) validity of the C-PSQ, the Goldberg Anxiety and Depression Scale (GADS, individually referred to as the GAS and GDS) was selected as a comparator scale, which shall be composed of a 9-item subscale that assesses symptoms of anxiety and a 9-item subscale that assesses symptoms of depression over the past month (Goldberg et al. 1988). All items can be answered with a simple "yes" or "no", with one or zero point respectively scored for each response. The final score is acquired by accumulating the response to each of the items, with higher values representing greater levels of symptomatology. The GADS has not only revealed good criterion validity for depressive disorders and generalised anxiety disorder but also displayed adequate values of sensitivity and specificity (Kiely \& Butterworth 2015; Mulhall et al. 2018; Pachana et al. 2007). Our team used this brief and friendly scale because it has been widely adopted as a standard to screen of anxiety and depression in large sample studies of the general population (Goldberg et al. 1988).

The formal investigation occurred from November 18, 2015, to January 6, 2016. We adopted the stratified sampling method to identify the sample of nursing students in Ningbo College of Health Science. In total, 1519 nursing students from 30 classes were surveyed. Among respondents, students in Grade 1 had studied nursing courses for more than 3 months, and students in Grade 3 had taken part in clinical practice in the hospital for more than 2 months. Simultaneously, we randomly chose a class to test the test-retest reliability of the C-PSQ. A total of 50 students in the class were tested three times including the formal survey, once per week; the final response rate was $100 \%$. To fully respect and protect the subjects' privacy, subjects' responses to our study were considered anonymous and confidential. The objective of the survey and the instructions for filling out the form were explained to the nursing students before the survey was conducted. All questionnaires were written and were collected once the subject finished writing. After excluding the unfinished and nonstandard questionnaires, a total of 1453 complete questionnaires were collected, for a response rate of $95.66 \%$.

\subsection{Statistical method}

A database was built by Epidata (version 3.1, Lauritsen JM \&Bruus M, Odense, Denmark) software. SPSS (version 18.0, SPSS Inc., Chicago, IL, USA), AMOS (version 18.0, SPSS Inc., Chicago, IL, USA) and Excel (version 2010, Microsoft, Redmond, USA) were adopted to analyse the data. Descriptive statistics were used to describe the demographic characteristics. Construct validity was tested by factor analysis, which was performed using principle components analysis with varimax transformation. Criterion (concurrent) validity and convergence values were evaluated by Spearman's correlations. Ten experts evaluated the content validity of the scale and found it acceptable (Lynn 1986). We chose Cronbach's coefficient to test the internal consistency 
206 of the scale and Spearman's correlations to assess the test-retest reliability. The (mean \pm SD) 207 represents the mean value; T-test or ANOVAs were used to compare the test or factor scores 208 between two or more groups. The significance level was set at or below $5 \%$.

209

\section{Results}

Characteristics of the subjects are described in Table 1. Nursing students' age ranged from 1723 years, with an average age of $19.58 \pm 1.09$. Their length of clinical practice experienced was 212 months, and the average length was $8.58 \pm 1.32$ months.

Table 1 Nursing students' demographic data $(\mathrm{N}=1453)$.

[Table 1 near here.]

The Kaiser-Meyer-Olkin measure of sampling adequacy (KMO) was 0.951, which means that the factor analysis was suitable (Kaiser \& Rice 1974). The common factors and component matrix of the principal component analysis are summarized in Table 2. The five extracted factors explained $52.136 \%$ of the total variance ( $>50 \%$ ), which was an acceptable level (Wu 2010). Factor 1 (Worries/Tension) includes 12 items $(9,12,14,15,18,19,20,22,26,27,28$, 30), factor 2 (Joy) includes 7 items $(1,10,13,17,21,25,29)$, factor 3 (Overload) includes 4 items $(4,8,11$, 16), factor 4 (Conflict) includes 5 items $(2,3,5,6,24)$, and factor 5 (Self- realization) includes 2 items $(7,23)$. The 5 factors described below formed the 5 dimensions of the scale.

Table 2 Communalities and rotated component matrix.

[Table 2 near here.]

Of the five extracted factors of the C-PSQ, items 2, 3, 5, 6 and 24 represented conflict, as they mainly revealed the socially acceptable degree of stress and psychological contradictions (Rönnlund et al. 2015; Sanz-Carrillo et al. 2002). Items 4, 8, 11 and 16 were named overload, as they mainly illustrated the stress caused by excess loads (Levenstein et al. 1993). Items 1, 10, 13, 17, 21, 25 and 29 were named joy, as they mainly presented a state that was joyful and energetic (Sanz-Carrillo et al. 2002); items on this dimension were reversely scored. Items 9, 12, 14, 15, $18,19,20,22,26,27,28$ and 30 revealed the worry and strain of the subjective; as it combined the dimensions of worries and tension in the original scale, we named it worries/tension (Levenstein et al. 1993). Items 7 and 23 represented self-realization, and thus we called it selfrealization (Sanz-Carrillo et al. 2002). We compared the scale's items clustering in the factors and factorial structure between the C-PSQ, English/Italian version of the PSQ and other versions of the PSQ. The results are shown in Table 3. 
237

238

239

240

241

242

243

244

Table 3 Comparison of factorial structure among different versions of the PSQ.

[Table 3 near here.]

The average Content Validity Index of the PSQ (S-CVI/Ave) was $0.913(>0.90)$, which means that the scale has good content validity (Polit \& Beck 2006). Taking the GADS as criterion, concurrent validity of the PSQ was 0.525 and 0.567 for anxiety and depression respectively. The results of construct validity of the PSQ displays in Table 4.

Table 4 Convergence values for the C-PSQ hierarchical factors structure.

[Table 4 near here.]

Based on the results of the factor analysis above, we conducted a confirmatory factor analysis to modify the model and formed Figure 2. In addition, the uncorrelated base model demonstrates in Figure 3. The results of the tests and the model's goodness of fit are shown in Table 5.

[Figure 2 near here.]

Figure 2 Confirmatory factor analysis the modified model model ( $\mathrm{n}=1453)$.

[Figure 3 near here.]

Figure 3 Confirmatory factor analysis the uncorrelated base model $(n=1453)$.

Table 5 Evaluation of the goodness of fit of the confirmatory factor analysis.

[Table 5 near here.]

From Table 5, we could see that the model's chi-square degree of freedom was 4.376; comprehensive assessments were made by referring to the goodness-fit index, as the result could be influenced by sample size (Kline 2016; Wheaton 1987). Indices that were within the standard range included $\mathrm{RMR}=.023, \mathrm{GFI}=.921, \mathrm{AGFI}=.907, \mathrm{CFI}=.916, \mathrm{RMSEA}=.048, \mathrm{PNFI}=.832$, $\mathrm{PGFI}=.782, \mathrm{CN}=342$ and $\mathrm{AIC} / \mathrm{CAIC}=.809$. The critical values for each of the fit indices (Byrne 2016) are RMR <.05, GFI> 9 (Hu \& Bentler 1999), AGFI> .9, CFI> 9 (Bentler 1990; Hu et al. 1995), RMSEA <.05 (good fit) or <.08 (reasonable) (Browne \& Cudeck 1993), PNFI>.5, PGFI $>.5, \mathrm{CN}>200(\mathrm{Hu}$ et al. 1995), lower is better concerning AIC/CAIC value(Wu 2010), respectively.

Cronbach's alpha of the C-PSQ was 0.922 CI $(0.916,0.928)$, which means that this scale has good internal consistency (Antonius 2003). Moreover, Cronbach's $\alpha$ values of the other 5 dimensions were all acceptable (Wu 2010), including 0.899 CI (0.891, 0.907), 0.821 CI (0.807, $0.835), 0.688 \mathrm{CI}(0.661,0.713), 0.703 \mathrm{CI}(0.678,0.726)$ and $0.523 \mathrm{CI}(0.472,0.570)$; namely 0.899 (worries/tension), 0.821 (joy), 0.688 (overload), 0.703 (conflict), 0.523 (self- realization). The scale has shown acceptable test-retest reliability. The correlation between the first and second test was $0.725 \mathrm{CI}(0.514,0.878)$, the correlation between the first and third test was $0.787 \mathrm{CI}$ $(0.607,0.890)$, and the correlation between the second and third test was $0.731 \mathrm{CI}(0.506,0.897)$. 
271 These results at one-week intervals proved that the scale has an appropriate level of both stability 272 and responsiveness to change over time. Reliability and validity of the PSQ in different nations 273 show that in Table 6.

274

Table 6 Description on different validity and reliability of the PSQ reported in original as well as different translated versions.

[Table 6 near here.]

Mean values and distribution of overall perceived stress score (PSQ index) in the surveyed students was $(0.399 \pm 0.138$, range $0.02-0.90)$. By using the two cut-off scores described below, the prevalence of perceived stress at a moderate level was estimated to be $10.3 \%$. The prevalence of perceived stress at high levels was $2.8 \%$. Of the responding students, 647 (44.5\%) thought that the greatest stress came from employment, and $543(37.4 \%)$ considered studying to be the greatest stress in college. Additionally, 49 students (3.4\%) attributed the greatest stress to love affairs, while 50 students (3.4\%) reported their financial situations. Eleven students (0.8\%) ascribed stress to other categories. We compared the perceived stress of nursing students with different characteristics (Table 7).

Table 7 Comparison of perceived stress in nursing students.

[Table 7 near here.]

\section{Discussion}

In the present study, the PSQ was translated and validated as well as applied in a large sample of nursing students. During the test-retest trial, the surveyed students reported engagement in different activities, including taking courses, skills training, sectional examinations and internship assignments. In particular, students were stressed during examinations and obtaining an internship, which we thought could influence their perceived stress and affect the final results. However, the results of the test-retest reliability were above .70, which meant that the scale are acceptable for research tools (Keszei et al. 2010) and had certain stability. The concurrent validity and Construct validity of the PSQ is not bad. Nonetheless, this result did not study using the same criterion as a reference. Therefore, the C-PSQ has an appropriate reliability and validity, which guarantees it as a suitable tool to measure the perceived stress of people in China.

$\chi^{2} / d f$ can be influenced by sample size, which was large in the current study. As a result, the $\chi^{2} / d f$ did not reach the appropriate standard (Hayduk 1987), but the results were acceptable, as they matched the flexible range ( <5) (Wu 2009). Moreover, other goodness-of-fit indexes of the model were all within the acceptable range, demonstrating that the scale's structure was stable.

As shown in Table 3, visible difference in the structure and items clustering in the factors are present among different versions of the PSQ but on some level several items of the PSQ (24, 4, 21,14 and 27) were happened to the cluster on a stability factor. In spite of this, the PSQ could be still translated into different languages and applied globally. Most of the fit statistics of the modified model is greater than the critical value and around half of fit statistics of the uncorrelated base model are not satisfactory in this study. We must admit that no matter which model's fitting effect is not great satisfactory, the modified model we reluctantly accept. Multi- 
310

country study showed that the results of exploratory factor analysis (EFA) are inconsistent after the PSQ was translated into local languages. There is reason to believe that the structural equation model may need to be further simplified. We will consider removing items (item reduction) (Fliege et al. 2005; Rönnlund et al. 2015) to optimize the structure of factors in future studies.

Furthermore, based on appropriate reliability and validity, we retained all 30 items of the original scale (Levenstein et al. 1993), thereby maintaining the high integrity of the original scale in obtaining an objective result. Moreover, the original English and Italian scales had advanced after twenty years of development, and items of the C-PSQ kept the same items as the original scale as well as the item order (Asencio-López et al. 2015; Levenstein et al. 2000; Levenstein et al. 1994; Levenstein et al. 1993). Including reversed scores for some of the items can detect false information. For example, when a subject chose "usually" as the answer for both "you feel rested" and "you feel tired", we judged the response as ineffective. In word, we need to extend the sample further research concerning reliability and validity of the PSQ.

Mean values and distribution of overall PSQ index in nursing students was $0.399 \pm 0.138$. This index was lower than that of ulcerative colitis patients in Susan Levenstein's research (Levenstein et al. 1994). Independent $t$-tests revealed that the differences were not statistical significant, $t=-$ 1.659, $P=0.097$. This index was higher than that of the general population (Sanz-Carrillo et al. 2002), $t=4.024, P=0.000$, and this difference was statistically significant. In the current study, nursing students' perceived stress levels were relatively high, which was consistent with the results of other studies (Lee \& Noh 2016; Ross et al. 2005). Appropriate stress can motivate students' enthusiasm to study and practice and can cultivate their confidence and optimism. However, students are forced to cope with stress when it becomes excessive (Findik et al. 2015). Whether the stress results in unhealthy physical and psychological change or abnormal behaviour depends on factors such as social support (school, family, friends and community) (Metzger et al. 2016) and self-adjustment (Saoji 2016). Therefore, it is necessary for nursing educators to recognize nursing students' stress and communicate with students to gradually build a support system for them. Leading and encouraging the students to develop mechanisms that facilitate optimism can help students manage stress and stay in a good mood.

Students whose initial educational degree was secondary school had lower perceived stress levels than students whose initial educational degree was high school. This could be explained by the previous nursing experience gained by secondary school graduates during their schooling. They became accustomed to the nursing field earlier than students who directly graduated from high school, and as students who directly graduated from high school were unfamiliar with the study of nursing, they became stressed. Moreover, students who participated in clinical practice had a lower perceived stress than those who did not; this result differed from other studies (AlZayyat \& Al-Gamal 2014; Moridi et al. 2014). Traditionally, people think that clinical practice is the greatest source of stress for nursing students. We speculated that students' perceived stress originated most from their fear of the many uncertain events that could happen during their internship, rather than their involvement in clinical practice. Students who are about to participate in their internship had a higher perceived stress, as they were worried and feared the difficulties they might face, whereas students who had participated in the internship had a lower perceived stress, as they were able to accomplish their work. 
Part-time jobs influenced nursing students in many ways (Lee et al. 1999). Students who worked part-time were under greater stress than those who did not. This might be because students who take part-time positions have a heavier economic burden than those who do not; they have to make a living through this work (Well et al. 2015). Moreover, role conflicts occur when students play many roles in their life, including student, worker, and friend (Yamada et al. 2011). Studies show that time spent on part-time position is inversely proportional to students' scores. Working 16 or more hours per week has a negative influence on students' academic achievements (Salamonson \& Andrew 2006). Working students' learning schedules could be occupied by their part-time job, thus leading to high levels of stress in studies and daily life.

Students who visited their home frequently had a lower perceived stress level than those who did not. Going back home can comfort nursing students through the provision of family support. One study showed that family support played an important role in medical students' life, especially when they were faced with a challenge. Family support encouraged students to face that challenge head-on and full of confidence (Klink et al. 2008). Furthermore, it can affect students' anxiety and depression (Wodka \& Barakat 2007), lower the incidence of depression (Harris \& Molock 2000) and positively affect the psychological health of students.

Students who were optimistic about their employment had a lower perceived stress than those who were not. Employment stress is determined by both inward and outward influencing factors and is closely related to the environment, physiology, psychology and behaviour (Hwang 2012; Yun \& Kim 2012). For instance, stress in academics and daily life can cause students to lack confidence and determination when needing to find employment. Additionally, in recent years, the job market has been stressful, which presents a challenge to Chinese nursing students.

Furthermore, students who could manage their emotions and were good at solving problems had a lower perceived stress than those who tended to avoid stress. One of the keys to success is knowing how to cope with stress and difficulties (Brady et al. 2016). Positive psychological interventions can be useful in reducing stress and improving confidence (Greeson et al. 2015; Heinen et al. 2017). One strategy to improve health status is promoting stress management capacity through training ( $\mathrm{Li}$ et al. 2016). One study showed that rational coping strategies were inversely proportional to perceived stress (Crego et al. 2016). Moreover, the students who were psychologically and physiological healthy had lower perceived stress levels than those who were not. Students' perceived stress can both influence and be influenced by their psychological and physiological health. Further studies should be conducted on the process of how stress influences psychological and physiological health.

\section{Conclusion}

The C-PSQ has an appropriate reliability and validity, which means that the scale can be used as a universal tool for psychosomatic studies. The perceived stress of nursing students was relatively high. In future research, it is necessary to further expand the sample to test different groups. Further studies are needed.

\section{Relevance for clinical practice}

The current study has translated the Perceived Stress Questionnaire (PSQ) into Chinese and applied it to nursing students. Results showed that nursing students' perceived stress level was 
394

relatively high which remind nursing educators to focus on students' stress. High level of stress makes students give up nursing study, educators should avoid this phenomenon which may cause the loss of clinical nurse and influence the nursing service quality. Further more, the PSQ could also be applied to clinical nurses by which the nursing managers could know the perceived stress of nurses. Nursing managers would relieve the stress of nurses which can ensure the smooth development of nursing work. We suggested that future studies should continuously monitor the dynamic stress level of nurses throughout their nursing career, specific interventions would be made in some special time of nodes at which the stress level is high. Such interventions would promote the development of nurses and improve the stability of the nursing team.

\section{Limitations and suggestions for future research}

Despite our efforts to completely explore validation and application of the CPSQ, we firmly believe that additional psychometrics indicators and influencing factors should be incorporated into further research done in the future.

1. Validation should include construct validity, criterion validity and content validity tests. There will be critical need also for action to find more evidence to prove that validity of the C-PSQ has stable and good validity. There are no adequate comparator scales to establish criterion validity and construct validity of the scale being assessed. The PSS may be a suitable criterion for testing in future studies.

2. The cross-sectional design of this study only tested nursing students, resulting in limited the inference of application range. As the PSQ is a universal scale, we need to measure different samples of more locations to confirm the C-PSQ applicability in China.

3. The PSQ belongs to a subjective measurement scale with respect to stress perception, which is easily affected by various factors, such as participants' cultural level and participation attitude. If further studies can be combined with objective indicators (physiological and biochemical index) as a criterion, thereby obtaining a more comprehensive criterion-related validity.

\section{Acknowledgement:}

Special thanks to Susan Levenstein MD from Aventino Medical group in Italy and Chua Yeewen from Department of Psychology, HELP University for their great help in the process of introducing the scale to China. We really appreciate that Susan Levenstein MD has taken time out of her schedule to comment on this paper. Meanwhile, we would like to acknowledge our friends Jingjing Li PhD Candidate from Rollins School of Public Health (RSPH), Emory University; Zhenkun Wang PhD from Tongji Hospital, Tongji Medical College, Huazhong University of Science and Technology; Yucong Ma who is a MTI of Southeast University-Monash University Joint Graduate School (Suzhou) and Di zhang who is a master student from School of Health Sciences, Wuhan University for their valuable assist in forward and back-translation. Also, we are grateful to all subjects taking part in the present study and teachers in Ningbo College of Health Sciences for their necessary assistance in collecting data. All authors appreciated the reviewers for constructive comments and suggestions to improve the quality of manuscript.

\section{References}

Al-Zayyat AS, and Al-Gamal E. 2014. Perceived stress and coping strategies among Jordanian nursing students during 
434

435

436

437

438

439

440

441

442

443

444

445

446

447

448

449

450

451

452

453

454

455

456

457

458

459

460

461

462

463

464

465

466

467

468

469

470

471

472

473

474

475

476

clinical practice in psychiatric/mental health courses. International journal of mental health nursing 23:326335.

Althubaiti A. 2016. Information bias in health research: definition, pitfalls, and adjustment methods. Journal of multidisciplinary healthcare 9:211.

Antonius R. 2003. Interpreting quantitative data with SPSS: Sage.

Asencio-López L, Almaraz-Celis G, Carrillo MV, Huerta VP, Silva GL, Muñoz TM, Monroy CF, Regalado TJ, Dipp MK, and López MD. 2015. Burnout syndrome in first to sixth-year medical students at a private university in the north of Mexico: descriptive cross-sectional study. Medwave 16:e6432-e6432.

Beddoe AE, and Murphy SO. 2004. Does mindfulness decrease stress and foster empathy among nursing students? Journal of nursing education 43:305-312.

Bentler PM. 1990. Comparative fit indexes in structural models. Psychological bulletin 107:238.

Bergdahl J, and Bergdahl M. 2002. Perceived stress in adults: prevalence and association of depression, anxiety and medication in a Swedish population. Stress and Health 18:235-241.

Brady ST, Reeves SL, Garcia J, Purdie-Vaughns V, Cook JE, Taborsky-Barba S, Tomasetti S, Davis EM, and Cohen GL. 2016. The psychology of the affirmed learner: Spontaneous self-affirmation in the face of stress. Journal of Educational Psychology 108:353.

Brislin RW. 1970. Back-translation for cross-cultural research. Journal of cross-cultural psychology 1:185-216.

Browne MW, and Cudeck R. 1993. Alternative ways of assessing model fit. In K. A. Bollen \& J. S. Long (Eds.), Testing structural equation models. Newbury Park, CA: Sage.

Byrne BM. 2016. Structural equation modeling with AMOS: Basic concepts, applications, and programming: Routledge.

Chen CJ, Chen YC, Sung HC, Hsieh TC, Lee MS, and Chang CY. 2015. The prevalence and related factors of depressive symptoms among junior college nursing students: a cross-sectional study. Journal of psychiatric and mental health nursing 22:590-598.

Chen Y-W, and Hung C-H. 2014. Predictors of Taiwanese baccalaureate nursing students' physio-psycho-social responses during clinical practicum. Nurse Education Today 34:73-77.

Consoli S, Taine P, Szabason F, Lacour C, and Metra P. 1996. Development and validation of a perceived stress questionnaire recommended as a follow-up indicator in occupational medicine. L'Encephale 23:184-193.

Crego A, Carrillo-Diaz M, Armfield JM, and Romero M. 2016. Stress and Academic Performance in Dental Students: The Role of Coping Strategies and Examination-Related Self-Efficacy. Journal of dental education 80:165172.

Doris S, Lee DT, and Woo J. 2003. Translation of the chronic heart failure questionnaire. Applied Nursing Research 16:278-283.

Findik UY, Ozbas A, Cavdar I, Topcu SY, and Onler E. 2015. Assessment of nursing students' stress levels and coping strategies in operating room practice. Nurse education in practice 15:192-195.

Fliege H, Rose M, Arck P, Levenstein S, and Klapp B. 2001. Validierung des "perceived stress questionnaire"(PSQ) an einer deutschen stichprobe. Diagnostica 47:142-152.

Fliege H, Rose M, Arck P, Walter OB, Kocalevent R-D, Weber C, and Klapp BF. 2005. The Perceived Stress Questionnaire (PSQ) reconsidered: validation and reference values from different clinical and healthy adult samples. Psychosomatic medicine 67:78-88.

Goetz CS. 1998. Are you prepared to SAVE your nursing student from suicide? Journal of nursing education 37:9295.

Goldberg D, Bridges K, Duncan-Jones P, and Grayson D. 1988. Detecting anxiety and depression in general medical 
477

478

479

480

481

482

483

484

485

486

487

488

489

490

491

492

493

494

495

496

497

498

499

500

501

502

503

504

505

506

507

508

509

510

511

512

513

514

515

516

517

518

519

settings. Bmj 297:897-899.

Greeson JM, Toohey MJ, and Pearce MJ. 2015. An Adapted, Four-Week Mind-Body Skills Group for Medical Students: Reducing Stress, Increasing Mindfulness, and Enhancing Self-Care. Explore: The Journal of Science and Healing 11:186-192.

Hamaideh SH, Al-Omari H, and Al-Modallal H. 2016. Nursing students' perceived stress and coping behaviors in clinical training in Saudi Arabia. Journal of Mental Health:1-7.

Harris TL, and Molock SD. 2000. Cultural orientation, family cohesion, and family support in suicide ideation and depression among African American college students. Suicide and Life-Threatening Behavior 30:341-353.

Hayduk LA. 1987. Structural equation modeling with LISREL: Essentials and advances: Jhu Press.

Heinen I, Bullinger M, and Kocalevent R-D. 2017. Perceived stress in first year medical students-associations with personal resources and emotional distress. BMC medical education 17:4.

Hu L-T, Bentler PM, and Hoyle RH. 1995. Evaluating model fit. In R. H. Hoyle (Ed.), Structural equation modeling: Concepts, issues, and applications. Thousand Oaks, CA: Sage.

$\mathrm{Hu}$ Lt, and Bentler PM. 1999. Cutoff criteria for fit indexes in covariance structure analysis: Conventional criteria versus new alternatives. Structural equation modeling: a multidisciplinary journal 6:1-55.

Hwang R-I. 2012. Factors affecting employment stress among college nursing students. Journal of Korean Public Health Nursing 26:215-226.

Kaiser HF, and Rice J. 1974. Little Jiffy, Mark IV. Educational and psychological measurement.

Karatza E, Kourou D, Galanakis M, Varvogli L, and Darviri C. 2014. Validation of the greek version of perceived stress questionnaire: Psychometric properties and factor structure in a population-based survey. Psychology 5:1268-1284.

Keszei AP, Novak M, and Streiner DL. 2010. Introduction to health measurement scales. Journal of psychosomatic research 68:319-323.

Kiely KM, and Butterworth P. 2015. Validation of four measures of mental health against depression and generalized anxiety in a community based sample. Psychiatry research 225:291-298.

Kline RB. 2016. Principles and practice of structural equation modeling. New York, NY: THE GUILFORD PRESS.

Klink JL, Byars-Winston A, and Bakken LL. 2008. Coping efficacy and perceived family support: potential factors for reducing stress in premedical students. Medical Education 42:572-579.

Kocalevent R-D, Levenstein S, Fliege H, Schmid G, Hinz A, Brähler E, and Klapp BF. 2007. Contribution to the construct validity of the Perceived Stress Questionnaire from a population-based survey. Journal of psychosomatic research 63:71-81.

Kocalevent RD, Hinz A, Brähler E, and Klapp BF. 2011a. Determinants of fatigue and stress. BMC research notes $4: 238$.

Kocalevent RD, Hinz A, Brahler E, and Klapp BF. 2011b. Regional and individual factors of stress experience in Germany: results of a representative survey with the perceived stress questionnaire (PSQ). Gesundheitswesen 73:829-834.

Lamaurt F, Estryn-Behar M, Le Moel R, Chrétien T, and Mathieu B. 2011. Survey on the satisfaction regarding their studies and the health habits of nursing students in France. Recherche en soins infirmiers:44-59.

Lee E-H. 2012. Review of the psychometric evidence of the perceived stress scale. Asian nursing research 6:121-127.

Lee E, and Noh HK. 2016. The Effects of a Web-Based Nursing Process Documentation Program on Stress and Anxiety of Nursing Students in South Korea. International journal of nursing knowledge 27:35-42.

Lee T, Mawdsley JM, and Rangeley H. 1999. Students' part-time work: towards an understanding of the implications for nurse education. Nurse education today 19:443-451. 
Levenstein S, Prantera C, Varvo V, Scribano ML, Andreoli A, Luzi C, Arca M, Berto E, Milite G, and Marcheggiano A. 2000. Stress and exacerbation in ulcerative colitis: a prospective study of patients enrolled in remission. The American journal of gastroenterology 95:1213-1220.

Levenstein S, Prantera C, Varvo V, Scribano ML, Berto E, Andreoli A, and Luzi C. 1994. Psychological stress and disease activity in ulcerative colitis: a multidimensional cross-sectional study. American Journal of Gastroenterology 89:1219-1225.

Levenstein S, Prantera C, Varvo V, Scribano ML, Berto E, Luzi C, and Andreoli A. 1993. Development of the Perceived Stress Questionnaire: a new tool for psychosomatic research. Journal of psychosomatic research 37:19-32.

Levenstein S, Rosenstock S, Jacobsen RK, and Jorgensen T. 2015. Psychological stress increases risk for peptic ulcer, regardless of Helicobacter pylori infection or use of nonsteroidal anti-inflammatory drugs. Clinical Gastroenterology and Hepatology 13:498-506. e491.

Levesque P. 2015. Meeting the Needs of the Transgender Nursing Student. Nurse educator 40:244-248.

Li F, Chen J, Yu L, Jing Y, Jiang P, Fu X, Wu S, Sun X, Luo R, and Kwan H. 2016. The Role of Stress Management in the Relationship between Purpose in Life and Self-Rated Health in Teachers: A Mediation Analysis. International Journal of Environmental Research and Public Health 13:719.

Lynn MR. 1986. Determination and quantification of content validity. Nursing research 35:382-386.

Metzger IW, Cooper SM, Ritchwood TD, Onyeuku C, and Griffin CB. 2016. Profiles of African American College Students' Alcohol Use and Sexual Behaviors: Associations With Stress, Racial Discrimination, and Social Support. The Journal of Sex Research:1-12.

Montero-Marin J, Demarzo MMP, Pereira JP, Olea M, and García-Campayo J. 2014. Reassessment of the psychometric characteristics and factor structure of the 'Perceived Stress Questionnaire'(PSQ): analysis in a sample of dental students. PloS one 9:e87071.

Moridi G, Khaledi S, and Valiee S. 2014. Clinical training stress-inducing factors from the students' viewpoint: A questionnaire-based study. Nurse education in practice 14:160-163.

Moscaritolo LM. 2009. Interventional strategies to decrease nursing student anxiety in the clinical learning environment. Journal of nursing education 48:17-23.

Mulhall S, Andel R, and Anstey KJ. 2018. Variation in symptoms of depression and anxiety in midlife women by menopausal status. Maturitas 108:7-12.

Østerås B, Sigmundsson H, and Haga M. 2015. Perceived stress and musculoskeletal pain are prevalent and significantly associated in adolescents: an epidemiological cross-sectional study. BMC public health 15:1081.

Pachana NA, Byrne GJ, Siddle H, Koloski N, Harley E, and Arnold E. 2007. Development and validation of the Geriatric Anxiety Inventory. International psychogeriatrics 19:103-114.

Patterson SL. 2016. The effect of emotional freedom technique on stress and anxiety in nursing students: A pilot study. Nurse education today 40:104-110.

Polit DF, and Beck CT. 2006. The content validity index: are you sure you know what's being reported? Critique and recommendations. Research in nursing \& health 29:489-497.

Rönnlund M, Vestergren P, Stenling A, Nilsson LG, Bergdahl M, and Bergdahl J. 2015. Dimensionality of stress experiences: Factorial structure of the Perceived Stress Questionnaire (PSQ) in a population-based Swedish sample. Scandinavian journal of psychology 56:592-598.

Rong XL, and Shi T. 2001. Inequality in Chinese education. Journal of Contemporary China 10:107-124.

Ross R, Zeller R, Srisaeng P, Yimmee S, Somchid S, and Sawatphanit W. 2005. Depression, stress, emotional support, and self-esteem among baccalaureate nursing students in Thailand. International Journal of Nursing 
Education Scholarship 2:Article25.

Salamonson Y, and Andrew S. 2006. Academic performance in nursing students: influence of part-time employment, age and ethnicity. Journal of advanced nursing 55:342-349.

Sanz-Carrillo C, Garcia-Campayo J, Rubio A, Santed M, and Montoro M. 2002. Validation of the Spanish version of the Perceived Stress Questionnaire. Journal of psychosomatic research 52:167-172.

Saoji AA. 2016. Yoga: A strategy to cope up stress and enhance wellbeing among medical students. North American journal of medical sciences 8:200.

Shearer RA, and Davidhizar RE. 1998. Recognizing a post-traumatic stress disorder in a nursing student. Journal of nursing education 37:222-224.

Sheu S, Lin H-S, and Hwang S-L. 2002. Perceived stress and physio-psycho-social status of nursing students during their initial period of clinical practice: the effect of coping behaviors. International Journal of Nursing Studies 39:165-175.

Sidani S, Guruge S, Miranda J, Ford-Gilboe M, and Varcoe C. 2010. Cultural adaptation and translation of measures: an integrated method. Research in nursing \& health 33:133-143.

Wachirawat W, Hanucharurnkul S, Suriyawongpaisal P, Boonyapisit S, Levenstein S, Jearanaisilavong J, Atisook K, Boontong T, and Theerabutr C. 2003. Stress, but not Helicobacter pylori, is associated with peptic ulcer disease in a Thai population. Journal of the Medical Association of Thailand= Chotmaihet thangphaet 86:672-685.

Waqas A, Khan S, Sharif W, Khalid U, and Ali A. 2015. Association of academic stress with sleeping difficulties in medical students of a Pakistani medical school: a cross sectional survey. PeerJ 3:e840.

Watson R, Gardiner E, Hogston R, Gibson H, Stimpson A, Wrate R, and Deary I. 2009. A longitudinal study of stress and psychological distress in nurses and nursing students. Journal of Clinical Nursing 18:270-278.

Well E, First F, it Out W, and Training CB. 2015. Warning over nursing students who resort to part-time jobs just to get by. Nursing Standard 29:8.

Wen D-m. 2005. The impacts of Chinese higher education expansion on graduate employment: an empirical analysis. Journal of Higher Education 26:25-30.

Wheaton B. 1987. Assessment of fit in overidentified models with latent variables. Sociological Methods \& Research 16:118-154.

Wodka EL, and Barakat LP. 2007. An exploratory study of the relationship of family support and coping with adjustment: Implications for college students with a chronic illness. Journal of adolescence 30:365-376.

Wu M-L. 2009. Structural Equation Model: the operation and application of AMOS: Chongqing University Press.

Wu M-L. 2010. Statistical analysis of the questionnaire: SPSS operation and Application. Chongqing: Chongqing University Press.

Yamada Y, Mizuno M, Ebara T, and Hirosawa M. 2011. Merits and demerits of engaging in athletic, academic and part-time job roles among university student-athletes in Japan. Journal of human ergology 40:141-150.

Yearwood E, and Riley JB. 2010. Curriculum infusion to promote nursing student well-being. Journal of advanced nursing 66:1356-1364.

Yun S-W, and Kim K-S. 2012. The Influence of University Students' Locus of Control on Stress towards Employment. Journal of the Korea Academia-Industrial cooperation Society 13:606-614. 
Figure 1

Flow chart of introducing the C-PSQ. 


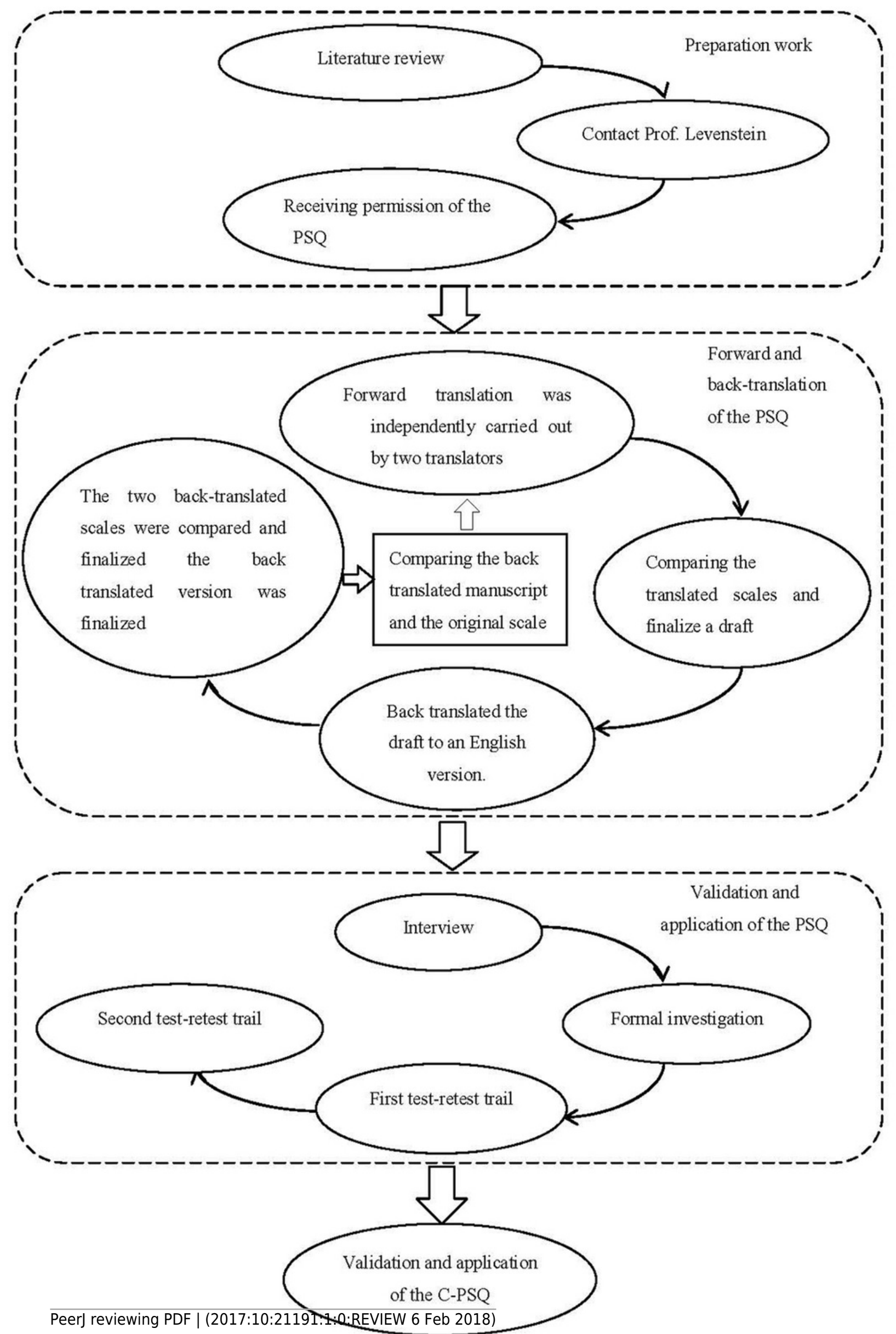


Figure 2

Confirmatory factor analysis the modified model model $(n=1453)$. 


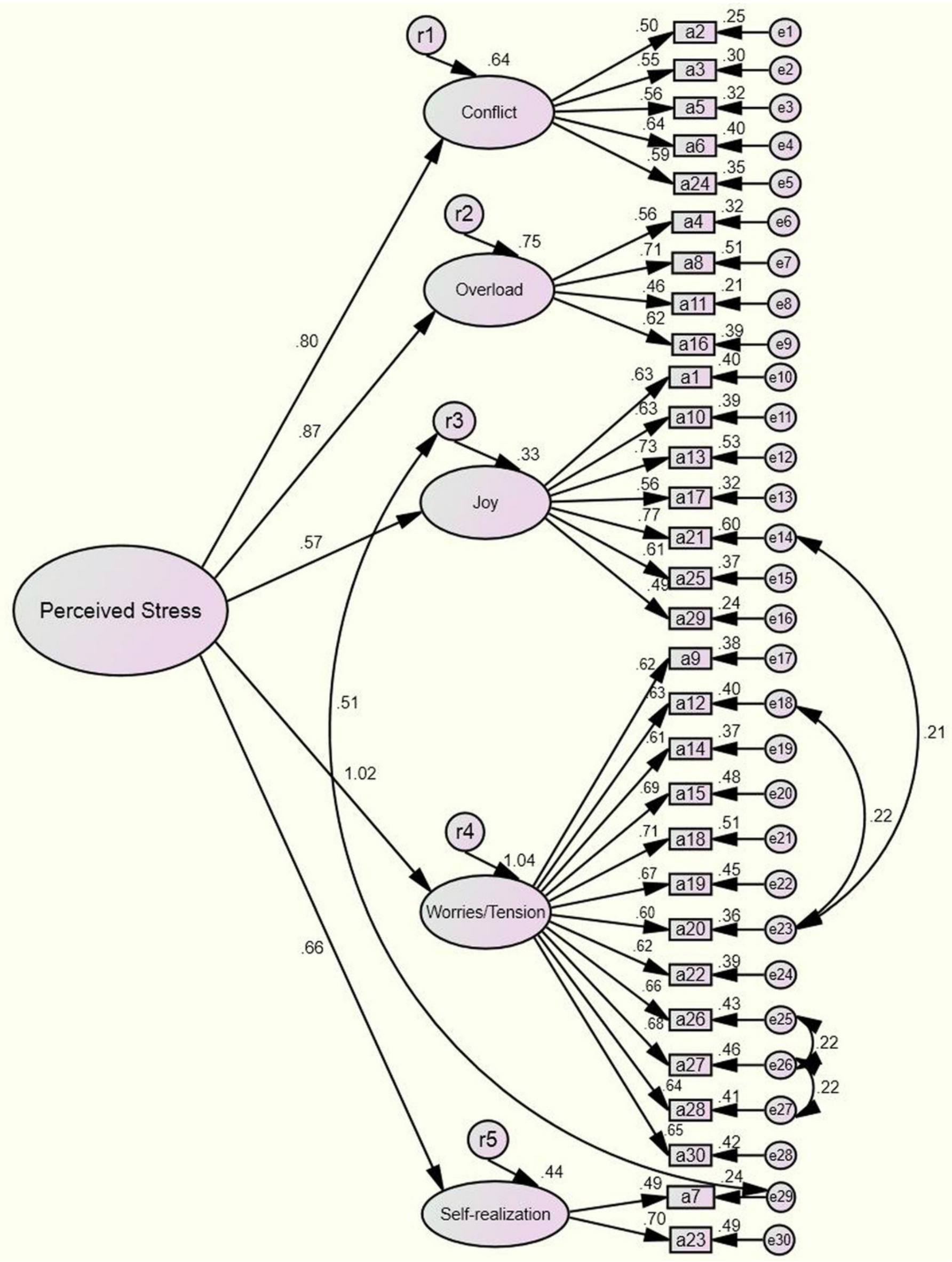


Figure 3

Confirmatory factor analysis the uncorrelated base model $(n=1453)$. 


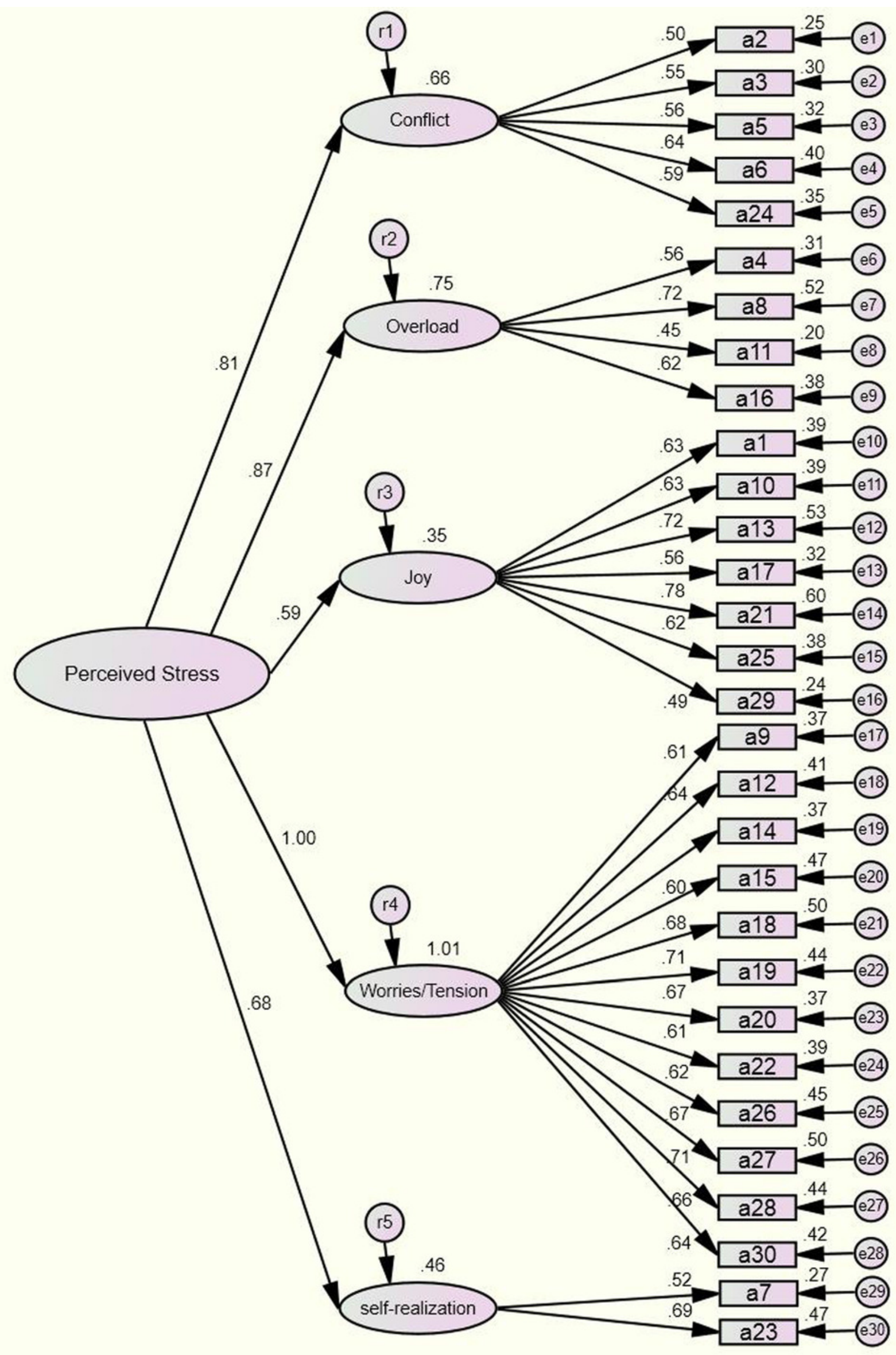




\section{Table 1 (on next page)}

Nursing students' demographic data $(\mathrm{N}=1453)$. 
Table 1 Nursing students' demographic data $(\mathrm{N}=1453)$.

\begin{tabular}{|c|c|c|}
\hline & & n (\%) \\
\hline \multicolumn{3}{|c|}{ Sex } \\
\hline & Male & $20(1.38)$ \\
\hline & Female & 1433(98.62) \\
\hline \multicolumn{3}{|c|}{ Age } \\
\hline & 17 & $8(0.55)$ \\
\hline & 18 & $239(16.45)$ \\
\hline & 19 & $457(31.45)$ \\
\hline & 20 & $469(32.28)$ \\
\hline & 21 & $209(14.38)$ \\
\hline & 22 & $69(4.75)$ \\
\hline & 23 & $2(0.14)$ \\
\hline \multicolumn{3}{|c|}{ Home location } \\
\hline & City & 194(13.35) \\
\hline & Town & $869(59.81)$ \\
\hline & Village & $390(26.84)$ \\
\hline \multicolumn{3}{|c|}{ Single-child status } \\
\hline & Yes & $473(32.55)$ \\
\hline & No & $980(67.45)$ \\
\hline \multicolumn{3}{|c|}{ Admission year } \\
\hline & 2015 & $603(41.50)$ \\
\hline & 2014 & $566(38.95)$ \\
\hline & 2013 & $284(19.55)$ \\
\hline \multicolumn{3}{|c|}{ Clinical practice status } \\
\hline & Yes & $653(44.94)$ \\
\hline & No & $800(55.06)$ \\
\hline
\end{tabular}


Table 2 (on next page)

Communalities and rotated component matrix. 
Table 2 Communalities and rotated component matrix.

$\begin{array}{ll}\text { Communalities } & \text { Component }\end{array}$

Factor 1 Factor 2 Factor 3 Factor 4 Factor 5

\begin{tabular}{ccccccc}
\hline $\mathbf{a 2 0}$ & .554 & .645 & .199 & -.010 & .307 & .062 \\
$\mathbf{a 2 2}$ & .532 & .634 & .130 & .068 & .190 & .268 \\
$\mathbf{a 2 8}$ & .558 & .620 & .249 & .244 & .198 & -.109 \\
$\mathbf{a 1 2}$ & .551 & .611 & .187 & .050 & .317 & .198 \\
$\mathbf{a 2 7}$ & .571 & .602 & .281 & .346 & .093 & -.005 \\
$\mathbf{a 1 9}$ & .522 & .593 & .120 & .371 & .136 & .020 \\
$\mathbf{a 1 4}$ & .427 & .551 & .131 & .302 & .087 & .083 \\
$\mathbf{a 1 8}$ & .543 & .543 & .217 & .399 & .122 & .160 \\
$\mathbf{a 3 0}$ & .533 & .531 & .094 & .440 & -.007 & .218 \\
$\mathbf{a 2 6}$ & .515 & .531 & .283 & .373 & .030 & .115 \\
$\mathbf{a 1 5}$ & .527 & .456 & .176 & .398 & .193 & .305 \\
$\mathbf{a 9}$ & .439 & .420 & .135 & .382 & .138 & .283 \\
$\mathbf{a 2 1}$ & .654 & .233 & .756 & -.043 & .142 & .080 \\
$\mathbf{a 1 3}$ & .583 & .189 & .702 & .009 & .092 & .215 \\
$\mathbf{a 2 5}$ & .485 & .201 & .647 & .151 & -.049 & .012 \\
$\mathbf{a 1 0}$ & .480 & .135 & .647 & .093 & .173 & .071 \\
$\mathbf{a 1}$ & .459 & .124 & .635 & .117 & .069 & .150 \\
$\mathbf{a 2 9}$ & .513 & .071 & .628 & .230 & -.018 & -.245 \\
$\mathbf{a 1 7}$ & .419 & .108 & .615 & -.033 & .137 & .095 \\
$\mathbf{a 4}$ & .572 & .064 & .094 & .729 & .149 & .070 \\
$\mathbf{a 1 1}$ & .427 & .238 & -.115 & .592 & .063 & -.052 \\
$\mathbf{a 8}$ & .564 & .279 & .295 & .563 & .144 & .248 \\
$\mathbf{a 1 6}$ & .433 & .345 & .067 & .538 & .104 & .099 \\
$\mathbf{a 5}$ & .554 & .276 & .113 & .010 & .682 & .007 \\
$\mathbf{a 3}$ & .502 & .088 & .144 & .342 & .571 & .175 \\
$\mathbf{a 2}$ & .524 & .095 & .115 & .402 & .565 & -.146 \\
$\mathbf{a 6}$ & .520 & .294 & .090 & .162 & .541 & .327 \\
$\mathbf{a 2 4}$ & .520 & .489 & .089 & -.018 & .522 & -.033 \\
$\mathbf{a 2 3}$ & .553 & .267 & .114 & .222 & .030 & .647 \\
\hline & .608 & .051 & .523 & .001 & .079 & .571 \\
\hline 04. & & & & & & \\
\hline
\end{tabular}

Note.

"a" represent item. 
Table 3 (on next page)

Comparison of factorial structure among different versions of the PSQ. 


\begin{tabular}{|c|c|c|c|c|c|}
\hline Original version & Spanish version & German version & Greece Version & Swedish version & Chinese version \\
\hline $\begin{array}{l}\text { Harrassment } \\
(2,6,19,24)\end{array}$ & $\begin{array}{l}\text { Harrassment- social } \\
\text { acceptance } \\
(5,6,12,17,19,20,24)\end{array}$ & - & $\begin{array}{c}\text { Harrassment } \\
(6,19,24)\end{array}$ & $\begin{array}{l}\text { Conflict } \\
(6,20,24)\end{array}$ & $\begin{array}{c}\text { Conflict } \\
(2,3,5,6,24)\end{array}$ \\
\hline $\begin{array}{c}\text { Overload } \\
(4,11,28,29)\end{array}$ & $\begin{array}{c}\text { Overload } \\
(2,4,11,18)\end{array}$ & $\begin{array}{c}\text { Demands } \\
(2,4,16,29,30)\end{array}$ & $\begin{array}{l}\text { Overload }(2,4,11, \\
16,18,25,28,30)\end{array}$ & $\begin{array}{c}\text { Demand } \\
(2,4,11,16,29,30)\end{array}$ & $\begin{array}{c}\text { Overload } \\
(4,8,11,16)\end{array}$ \\
\hline $\begin{array}{l}\text { Irritability } \\
(3,10)\end{array}$ & $\begin{array}{c}\text { Irritability- tension- fatigue } \\
(1,3,8,10,14,15,16,26,27 \\
30)\end{array}$ & - & & - & - \\
\hline $\begin{array}{c}\text { Lack of joy } \\
(5,7,16,17,21,23,25)\end{array}$ & $\begin{array}{c}\text { Energy- joy } \\
(1,13,21,25,29)\end{array}$ & $\begin{array}{c}\text { Joy } \\
(7,13,17,21,25)\end{array}$ & $\begin{array}{c}\text { Joy }(1,7,13,17,21, \\
29)\end{array}$ & $\begin{array}{c}\text { Lack of joy } \\
(10,17,21,25)\end{array}$ & $\begin{array}{c}\text { Joy } \\
(1,10,13,17,21,25,29)\end{array}$ \\
\hline $\begin{array}{c}\text { Fatigue } \\
(1,8,13,15)\end{array}$ & - & - & $\begin{array}{l}\text { Tension- Fatigue }(3, \\
5,8,10,14,26,27)\end{array}$ & $\begin{array}{l}\text { Fatigue } \\
(1,8,13)\end{array}$ & - \\
\hline Worries & Fear- anxiety & Worries & Worries & & \\
\hline$(9,18,20,22,30)$ & $(22,28)$ & $(9,12,15,18,22)$ & $(9,12,15,20,22,23)$ & Worries/tension & Worries/Tension \\
\hline $\begin{array}{c}\text { Tension } \\
(12,14,26,27)\end{array}$ & - & $\begin{array}{c}\text { Tension } \\
(1,10,14,26,27)\end{array}$ & & $(9,14,22,27)$ & $\begin{array}{c}(9,12,14,15,18,19,20, \\
22,26,27,28,30)\end{array}$ \\
\hline - & $\begin{array}{l}\text { Self- realisation- satisfaction } \\
\qquad(7,9,23)\end{array}$ & - & & - & $\begin{array}{c}\text { Self- realization } \\
(7,23) \\
\end{array}$ \\
\hline
\end{tabular}

Table 3 Comparison of factorial structure among different versions of the PSQ.

Note: C-PSQ (2017), the Greece version (2014) and the Spanish version (2002) keeps all the 30 items of the original version (1993) while the German version (2005) keeps 20 items and the Swedish version (2015) keeps 21 items of the original scale. 
Table 4 (on next page)

Convergence values for the C-PSQ hierarchical factors structure. 
Table 4 Convergence values for the C-PSQ hierarchical factors structure.

\begin{tabular}{ccccccccc}
\hline & rg & Mean & SD & Factor 1 & Factor 2 & Factor 3 & Factor 4 & Factor 5 \\
\hline Perceived Stress & $0-1$ & 0.399 & 0.138 & 0.913 & 0.735 & 0.678 & 0.715 & 0.563 \\
Anxiety & $0-9$ & 4.503 & 2.441 & 0.499 & 0.396 & 0.347 & 0.386 & 0.268 \\
Depression & $0-9$ & 3.577 & 2.343 & 0.549 & 0.435 & 0.343 & 0.390 & 0.316 \\
\hline
\end{tabular}

Note. rg, range; SD, standard deviation; Anxiety and Depression from GADS; Convergence values are Spearman's R correlations; All $P$ values are less than 0.01; Correlation is significant at the 0.01 level (2-tailed). 


\section{Table 5 (on next page)}

Evaluation of the goodness of fit of the confirmatory factor analysis. 
Table 5 Evaluation of the goodness of fit of the confirmatory factor analysis.

\begin{tabular}{|c|c|c|c|c|c|}
\hline Index & Test result $^{\triangle}$ & Model fit judgement $^{\Delta}$ & Test result $^{\wedge}$ & Model fit judgement ${ }^{\boldsymbol{\Delta}}$ & Standard and critical value \\
\hline$\chi^{2} / d f$ & 4.376 & $\begin{array}{c}\text { No (Probably caused by the } \\
\text { large sample) }\end{array}$ & 5.668 & $\begin{array}{c}\text { No (Probably caused by the } \\
\text { large sample) }\end{array}$ & $<3$ \\
\hline RMR & .023 & Yes & .030 & Yes & $<.05$ \\
\hline GFI & .921 & Yes & .896 & No & $>.9$ \\
\hline AGFI & .907 & Yes & .879 & No & $>.9$ \\
\hline CFI & .916 & Yes & .882 & No & $>.9$ \\
\hline RMSEA & .048 & good fit & .057 & reasonable & $\begin{array}{l}<.05(\text { good fit }) \\
<.08 \text { (reasonable })\end{array}$ \\
\hline PNFI & .832 & Yes & .791 & Yes & $>.5$ \\
\hline PGFI & .782 & Yes & .771 & Yes & $>.5$ \\
\hline $\mathbf{C N}$ & 342 & Yes & 287 & Yes & $>200$ \\
\hline AIC/CAIC & .809 & relatively small & .854 & relatively large & relatively small \\
\hline
\end{tabular}

Notes:

$\chi^{2} / d f$, differences in chi-square by $d f$ (all $p<.001$ ); RMR, root mean square residual; GFI, goodness-of-fit index; AGFI, adjusted goodness-of-fit index; CFI, comparative fit index; RMSEA, root mean square error of approximation; PNFI, parsimony-adjusted NFI; PGFI, parsimony goodness-of-fit index; CN, Critical $\mathrm{N} ; \mathrm{AIC}=$ Akaike information criterion; $\mathrm{CAIC}=$ consistent Akaike information criterion; $\triangle$ the modified model; $\boldsymbol{\Delta}$ the uncorrelated base model. 


\section{Table 6(on next page)}

Description on different validity and reliability of the PSQ reported in original as well as different translated versions. 
Table 6 Description on different validity and reliability of the PSQ reported in original as well as different translated versions.

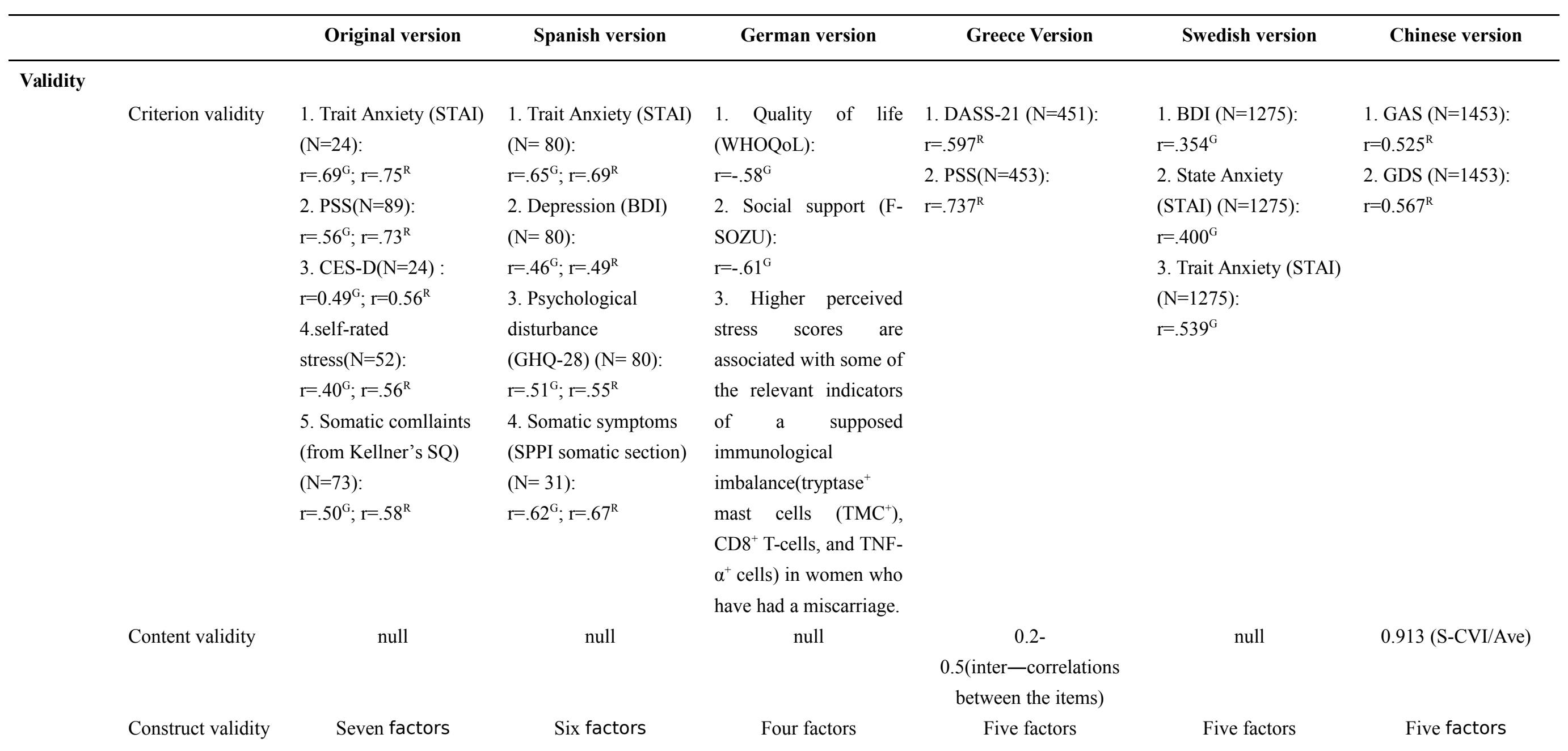




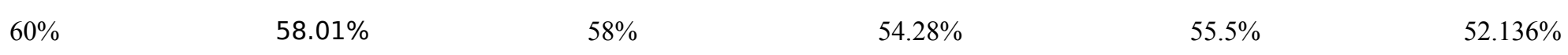

Reliabilit

$\mathbf{y}$

Coefficient alpha

$.90^{\mathrm{G}} ; .92^{\mathrm{R}}$

Test-retest
$.82^{\mathrm{G}}$

$8.03 \pm 1.64$ days, $\mathrm{N}=101$
$.90^{\mathrm{G}} ; .87^{\mathrm{R}}$

$.80^{\mathrm{G}}$

$13.12 \pm 2.05$ days, at least $.85^{\mathrm{G}}$

(reliability at least .80)

null
$.90^{\mathrm{R}}$

$.86^{\mathrm{R}}$

one month, $\mathrm{N}=212$
$.90^{\mathrm{G}}$

null
$0.922^{\mathrm{R}}$ $0.725^{\mathrm{R}}$ one week, $\mathrm{N}=50$ $\mathrm{N}=176$

\section{Note.}

1. STAI = the State-Trait Anxiety Inventory, PSS $=$ the Perceived Stress Scale, CES-D $=$ the Center for Epidemiologic Studies Depression, BDI $=$ the Beck Depression Inventory, GHQ-28 = the General Health Questionnaire-28 items, DASS-21 = the Depression Anxiety Stress Scale(a short version); GADS $=$ GAS + GDS = the Goldberg Anxiety and Depression Scale;

2. G represents the General PSQ; R means the Recent PSQ. 
Table 7 (on next page)

Comparison of perceived stress in nursing students. 
Table 7 Comparison of perceived stress in nursing students.

\begin{tabular}{|c|c|c|c|c|}
\hline & $\mathbf{n}$ & Mean \pm SD & $t / \mathbf{F}$ & $\boldsymbol{P}$ \\
\hline Initial educational degree & & & -9.749 & 0.000 \\
\hline Secondary school & 319 & $0.334 \pm 0.123$ & & \\
\hline High school & 1134 & $0.417 \pm 0.136$ & & \\
\hline Clinical practice & & & -8.823 & 0.000 \\
\hline Yes & 653 & $0.364 \pm 0.127$ & & \\
\hline No & 800 & $0.427 \pm 0.140$ & & \\
\hline Part time job & & & 4.816 & 0.000 \\
\hline Yes & 570 & $0.420 \pm 0.140$ & & \\
\hline No & 883 & $0.385 \pm 0.135$ & & \\
\hline Frequency of going home & & & 5.348 & 0.001 \\
\hline$<1 / 2$ month & 311 & $0.380 \pm 0.130$ & & \\
\hline$<1$ month & 465 & $0.390 \pm 0.139$ & & \\
\hline$<1$ season & 305 & $0.410 \pm 0.134$ & & \\
\hline$<1$ semester & 372 & $0.417 \pm 0.143$ & & \\
\hline Physical health & & & 69.537 & 0.000 \\
\hline Very good & 334 & $0.336 \pm 0.126$ & & \\
\hline Good & 779 & $0.393 \pm 0.126$ & & \\
\hline Average & 316 & $0.469 \pm 0.137$ & & \\
\hline Bad & 24 & $0.551 \pm 0.156$ & & \\
\hline Mental health & & & 134.761 & 0.000 \\
\hline Very good & 391 & $0.324 \pm 0.124$ & & \\
\hline Good & 737 & $0.394 \pm 0.118$ & & \\
\hline Average & 300 & $0.489 \pm 0.128$ & & \\
\hline Bad & 25 & $0.631 \pm 0.134$ & & \\
\hline Prospect of employment & & & 45.702 & 0.000 \\
\hline Very good & 106 & $0.325 \pm 0.139$ & & \\
\hline Good & 683 & $0.373 \pm 0.127$ & & \\
\hline Average & 608 & $0.431 \pm 0.136$ & & \\
\hline Bad & 56 & $0.512 \pm 0.133$ & & \\
\hline Coping skill & & & 48.516 & 0.000 \\
\hline Adjusting psychology & 968 & $0.388 \pm 0.131$ & & \\
\hline Solving problems & 369 & $0.390 \pm 0.138$ & & \\
\hline Escaping & 116 & $0.516 \pm 0.138$ & & \\
\hline
\end{tabular}

Note. 
Secondary school and high school represent the educational degree before college degree. $t / \mathrm{F}$, we chose " $t$ " to compare the differences between the two groups; we used " $F$ " to compare differences between more than two groups. 